\title{
ACM Annual Report for FY07
}

I

$\mathrm{n}$ recent months we have celebrated ACM's 60th Anniversary and the 50th Anniversary of its flagship publication, Communications of the $A C M$. Both events signify the enduring role ACM has played as the conduit for the world's educators, researchers, and professionals to share their common computing interests, inspire new innovation, and reveal their latest research. Indeed, ACM's steadfast commitment to advancing computing as a science and profession worldwide can be traced from the first days of the ENIAC, to improving today's quality of life, to encouraging and educating future generations to join a field of countless opportunities.

In the past year, major corporations have endorsed ACM's global influence in recognizing technical excellence by sponsoring or increasing the cash value of a number of the Association's prestigious awards. The financial value of the A.M. Turing Award, certainly the computing field's greatest and most visible honor, will increase from $\$ 100,000$ to $\$ 250,000$, thanks to the generosity of co-sponsors Intel and Google. IBM increased ACM's Software System Award to $\$ 35,000$. The Doctoral Dissertation Award, now sponsored by Google, is $\$ 20,000$ for first place, and $\$ 10,000$ for second place. And Google raised its sponsorship of the Grace Murray Hopper Award to $\$ 35,000$.

Moreover, ACM recently announced the creation of a new honor, the ACMInfosys Foundation Award, recognizing younger scientists whose innovations are having a dramatic impact on the computing field. The award will carry a prize of $\$ 150,000$, and was endowed by the Infosys Foundation.

ACM's global outreach has never been stronger, as witnessed by the growth in the number of technical conferences, professional chapters, and Special Interest Group initiatives taking root overseas this year. The Association's devotion to forging professional relationships worldwide was solidified by meetings to establish an ACM presence in the major technology hubs of China and India. ACM's China Task Force held its first two meetings in FY07. An agreement was reached with Tsinghua University to establish an ACM office in Beijing as a focal point for the Association's presence in China. ACM's India Task Force met in Bangalore recently to explore how best to serve this burgeoning audience.

In the coming year, $\mathrm{ACM}$ will continue to foster these critical global relationships, as well as build new bridges to connect the computing interests of its international membership, and create new services and products to meet their professional needs. We are working on expanding services for practitoners and a radically improved Communications.

As always, we are indebted to ACM's dedicated volunteers, members, staff, and industry partners for their ongoing support in turning promises into reality.

Stuart I. Feldman ACM President 
ACM, the Association for Computing Machinery, is an international scientific and educational organization dedicated to advancing the art, science, engineering, and application of information technology.

\section{Publications}

ACM's Digital Library and Guide to Computing Literature continue to flourish in content, usage, and prestige, and remain in great demand worldwide. The number of full-text articles in the DL as of June 2007 was 209,000 and the Guide's bibliographic database increased to over one million entries.

Two new journals were launched in FY07: Transactions on Knowledge Discovery in Data (TKDD) and Transactions on the Web (TWeb). In addition, the ACM Publications Board approved two new publications: $A C M$ Transactions on Reconfigurable Systems (TRES), and ACM Transactions on Computation Theory (ToCT).

The Publications Board also assembled a group of digital library experts to examine ways to enrich the functionality and services available from ACM's DL product. The discussions, which focused on areas such as search and retrieval technology, open-access, and user-interface improvements, culminated in a list of recommendations for ACM to consider.

Efforts to revitalize the editorial model of Communications of the ACM remained in full swing, with focus groups and volunteers coming together throughout the year to exchange ideas for enhancing ACM's premier publication. Details of these discussions and the subsequent plan were published in the January 2008 issue of Communications, page 44.

ACM Queués "Queuecasts" had a very successful inaugural year. These podcasts, available via the magazine's Web site (www. acmqueue. org/), feature industry experts in 15-minute conversations on timely topics.

\section{Education}

A new Education Policy Committee (EPC) was formed to influence education policy on behalf of the computing community. The primary focus of the committee is education and advocacy in K-12 science, technology, engineering, and mathematics (STEM) education. The EPC's initial efforts will address the quality and availability of computer science education at the high school level.

The Computer Science Teachers Association (CSTA) continues to support and promote opportunities for $\mathrm{K}-12$ teachers and students to better understand the computing disciplines. CSTA issued a second edition of $A$ Model Curriculum for K-12 Computer Science, designed to set the context for computer science within current $\mathrm{K}-12$ education and provide a framework for preparing young students for personal and professional opportunities in the 21 st century.

A new brochure to counter the many misperceptions about computing circulating among high school students, their parents, and teachers was prepared jointly by ACM, IEEE Computer Society, and the Association for Information Systems. "Computing Degrees and Careers," provides more accurate information about computing and the career opportunities it offers. 


\section{Professional Development}

The diverse offerings available from the Professional Development Centre were enhanced dramatically last year with the expansion of ACM's Online Books and Courses programs. Members now have access to over 1,100 books from Safari and Books24X7-a valuable resource providing reference works on a broad range of subjects in technology, project management, and business.

Web-based professional development courses available for ACM members grew to over 2,200 in FY07. These courses, from leading provider Skill Soft, cover a wide selection of topics from information technology and business opportunities.

ACM's Career and Job Center, powered by JobTarget, offers members the opportunity to view and apply for a variety of highly targeted technology jobs, including hundreds of corporate job postings often not seen on commercial sites. Members can post resumes, create and receive job alerts, and receive live career advice.

The Professions Board is hoping to launch its Best Practices community Web site in the near future. Steady progress was made this year in creating a site to provide answers to practical questions about technologies, approaches, tools, and processes by creating a community where IT professionals can discuss qualified solutions to problems.

\section{Public Policy}

ACM's U.S. Public Policy Committee
(USACM) continued its efforts to advance the computing discipline by finding a balance between innovation, intellectual property protection, and privacy issues; and for secure and reliable computing systems. Several committee members testified before Congress on the need to reform e-voting policy, the use of large-scale IT systems for identity and employment verification, and the privacy risks of using Social Security numbers in databases. Committee members and Policy Office staff briefed Congressional members on the threat of botnets, the technical issues in a proposed electronic employment verification system, and e-voting. In addition, USACM submitted detailed comments on the security risks inherent in the REAL ID program for new driver's licenses introduced by the Department of Homeland Security. For more information about USACM's activities, visit www.acm.org/usacm/annualreports/index. html.

The Committee on Computers and Public Policy (CCPP) serves ACM with respect to a variety of internationally relevant issues pertaining to computing. The committee works to create and maintain global online forums to share and discuss public policy concerns.

\section{STUDENTS}

The 31st Annual ACM International Collegiate Programming Contest World Finals was sponsored by IBM and hosted by ACM's Japan Chapter and IBM Tokyo Research Lab. 
The preliminaries drew 6,099 teams from 1,756 universities representing 82 countries. Some 88 teams made it to the finals and the 2006 winners were from Warsaw University.

The ACM Student Research Competition is an internationally recognized venue enabling undergraduates and graduate students to share research results and exchange ideas with other students, judges, and conference attendees and understand the practical applications of their research. Rounds of competition are held at a variety of ACM conferences throughout the year.

ACM's Committee on Women in Computing (ACM-W) will provide financial support for undergraduate or graduate women students in CS programs who are interested in attending research conferences. Initially, up to 12 scholarships of about $\$ 500$ each will be awarded annually.

SIGARCH made a one-time grant of $\$ 100 \mathrm{~K}$ toward the endowment of a fellowship for Ph.D. students in high-performance computing.

\section{Conferences}

The Federated Computing Research Conference, held every four years as an umbrella meeting ground for a wide spectrum of affiliated research conferences and workshops, drew a record number of attendees. In fact, most of the conferences within FCRC ' 07 exceeded attendance expectations.

SIGGRAPH 2006, held in Boston, also exceeded attendance expectations, registering almost 20,000 artists, researcher scientists, developers, filmmakers, and academics from 80 countries. More than 230 companies exhibited, including 76 first-time exhibitors.

ASSETS 2006 featured novel computer applications for attendees with disabilities. Assistive technology research from the University of Washington was available for people with hand and hearing limitations, including the vocal joystick and a sign language cell phone that employs video compression.

\section{Local Activities}

The Membership Services Board chartered 41 new chapters in FY07, six of which were international professional chapters. Of the 35 new student chapters, 11 were internationally based.

\section{INTERNATIONAL}

Great inroads were made in ACM's initiatives to establish roots in the major technology centers of China and India. A China Task Force and India Task Force were established this year and initial meetings were held to build professional relationships and secure the best methods for sharing ACM's publications, services, and resources with these influential countries.

CSTA has been working on outreach programs with Mexico and several European associations. Moreover, CSTA hosted a workshop in Great Britain that examined issues 
related to $\mathrm{K}-12$ education, and plans for a joint symposium in Israel are under way for later this year.

The Education Board has been working to broaden European participation in computing education activities. The Board worked in an international advisory capacity with the European Union-funded Euro-Inf project, which was established to devise criteria for the accreditation of degrees in informatics across Europe at the undergraduate and masters level.

SIGGRAPH approved the concept of a new conference in Asia. The first SIGGRAPH Asia will be held at the end of the year in Singapore.

SIGMOD is making a determined effort to expand its international initiatives. Their initial steps forged close relationships with societies throughout Europe, China, and Japan.

\section{EleCtRonic COMmUNITY}

The ACM History Committee revamped its Web site (www.acm.org/history.acm.org) and has made the first set of oral histories of former ACM Presidents and Turing Award recipients available in the Digital Library. Each interview is conducted by a professional historian and provides a sense of the ACM's role in computing history, as the interviews parallel the development of the field.

The Education Board and CSTA joined forces to create a dynamic Web site offering information on educational and career options in the computing field. The online material is designed for high school students and educators and is available in English and Spanish.

SIGWEB has been building new memberonly services into its Web site and expanding the information found within. New features of its site include a collection of relevant Ph.D. dissertations and a series of interviews with active researchers from the SIGWEB community.

\section{RECOGNITION}

The ACM Fellows Program, established in 1993 to honor outstanding ACM members for their achievements in computer science and IT, inducted 41 new fellows in FY07, bringing the total count to 594 .

The first recipients of ACM's distinguished member grades were announced last spring. The Association recognized 77 Senior Members who have at least 10 years of professional experience and who have demonstrated performance and accomplishment that set them apart from their peers. ACM also recognized 17 Distinguished Engineers, 24 Distinguished Scientists, and eight Distinguished Members - all having the distinction of at least 15 years of professional experience and who have demonstrated significant accomplishments or made a significant impact on the computing field.

The first recipients of the Frank Anger Memorial SIGBED/SIGSOFT Student Award were announced in FY07. The award promotes interdisciplinary research between embedded systems and software engineering. 
BALANCE SHEET

JUNE 30, 2007 (IN THOUSANDS)

ASSETS:

CASH AND CASH EQUIVALENTS

$\$ 21,328$

INVESTMENTS

ACCOUNTS RECEIVABLE AND OTHER CURRENT ASSETS

47,406

4,008

I, 250

DEFERRED CONFERENCE EXPENSES AND OTHER ASSETS

5,192

FiXed ASSETS, NET OF ACCUMULATED DEPRECIATION AND AMORTIZATION

2,022

TOTAL ASSETS

\section{LIABILITIES AND NET ASSETS:}

LIABILITIES:

ACCOUNTS PAYABLE, ACCRUED EXPENSES, AND OTHER LIABILITIES

$\$ 7,876$

UNEARNED CONFERENCE, MEMBERSHIP, AND SUBSCRIPTION REVENUE

I9, 076

TOTAL LIABILITIES

26,952

Net Assets:

UNRESTRICTED

48,796

TEMPORARILY RESTRICTED

TOTAL NET ASSETS

TOTAL LIABILITIES AND NET ASSETS

5,458

54,254

$\$ 8$ I ,206

OPTIONAL CONTRIBUTIONS FUND - PROGRAM EXPENSES (\$OOO)

EDUCATION BOARD ACCREDITATION

$\$ 50$

USACM COMMITTEE

20

TOTAL EXPENSES

$\$ 70$ 


\section{STATEMENT OF ACTIVITIES}

YEAR ENDED JUNE 3O, 2007 (IN THOUSANDS)

$\begin{array}{lll}\text { UnRestricted } & \text { Temporarily } & \text { Total } \\ \text { Net assets } & \text { Restricted } & \\ & \text { Net assets } & \end{array}$

\section{REVENUE:}

Membership DUES

Publications

CONFERENCES AND OTHER MEETINGS

INTEREST AND DIVIDENDS

NET APPRECIATION OF INVESTMENTS

CONTRIBUTIONS AND GRANTS

OTHER REVENUE

NET ASSETS RELEASED FROM RESTRICTIONS

TOTAL REVENUE

$$
\begin{array}{r}
\$ 8,832 \\
\mathrm{I} 4, \mathrm{I} 3 \mathrm{I} \\
23,530 \\
2, \mathrm{I} 2 \mathrm{I} \\
3,694 \\
3, \mathrm{I} 08 \\
2 \mathrm{I} 8 \\
665 \\
\$ 56,299
\end{array}
$$

\section{EXPENSES:}

\section{PROGRAM:}

Membership PROCESSING AND SERVICES

Publications

CONFERENCES AND OTHER MEETINGS

PROGRAM SUPPORT AND OTHER

TOTAL PROGRAM EXPENSES

SUPPORTING SERVICES:

General Administration

MARKETING

\section{TOTAL EXPENSES}

INCREASE (DECREASE) IN NET ASSETS

Net assets at THE BEgINNING OF THE YEAR

NET ASSETS AT END OF YEAR

*INCludes SIG FUND BALANCE OF \$23,939
$\$ 889$

I, 683

$2 \mathrm{I}, \mathrm{OI} 2$

5,992

$\$ 38,586$

$\$ 8,708$

I, 394

$\$ 48,688$

7,6 I I

4 I, I 85

$\$ 48,796 *$
$\$ 8,832$

I 4 , I 3 I

23,530

2, I 2 I

3,694

8, I97

2 I 8

-----

$\$ 60,723$
$\$ 889$

I, 683

2 I, O I 2

5,992

$\$ 38,586$

8,708

I, 394

48,688

I 2,035

42,2 I9

$\$ 54,254 *$ 


\section{ACM COUNCIL}

PRESIDENT Stuart I. Feldman

Vice President Wendy Hall

Secretary/Treasurer Alain Chesnais

Past President DavidA. Patterson

Sig Governing Board Chair Joseph A. Konstan

Publications Board Co-Chairs Ronald Boisvert, Mary Jane Irwin

Members-At-Large Michel Beaudouin-Lafon, Bruce Maggs

Barbara Ryder, Kevin Scott

Jeanette Wing, David S. Wise

SGB Council Representatives

Norman Jouppi, Robert A. Walker Alexander Wolf

ACM HEADQUARTERS

Executive Director/CEO

John R. White

Deputy Executive Director/COO

\section{ACM AWARD RECIPIENTS}

A.M. Turing Award Frances E. Allen

ACM/AAAI Allen Newell Award

Grace Murray Hopper Award

Karen Spärck Jones

Daniel Klein

ACM-IEEE CS ECKERT-MaUChLy Award

Mateo Valero

OUtSTANDING CONTRIBUTION

TO ACM AWARD

Distinguished Service Award

David S. Wise

Susan L. Grabam

Paris Kanellakis TheOrY aND

Practice Award

ACM President's Award

Software System AWARd

Robert Brayton

Eugene H. Spafford

Bertrand Meyer

SIAM/ACM AWARD IN COMPUTATIONAL

SCIENCE AND ENGINEERING

Doctoral Dissertation Award

Honorable Mention

Chi-Wang Shu

Yi-Ren $\mathrm{Ng}$

Aseem Agarwala 